\title{
Daily access to sucrose impairs aspects of spatial memory tasks reliant on pattern separation and neural proliferation in rats
}

\author{
Amy C. Reichelt, ${ }^{1,3}$ Margaret J. Morris, ${ }^{2}$ and Reginald Frederick Westbrook ${ }^{1}$ \\ ${ }^{1}$ School of Psychology; ${ }^{2}$ School of Medical Sciences, UNSW Australia, UNSW Sydney, New South Wales 2052, Australia
}

\begin{abstract}
High sugar diets reduce hippocampal neurogenesis, which is required for minimizing interference between memories, a process that involves "pattern separation." We provided rats with $2 \mathrm{~h}$ daily access to a sucrose solution for $28 \mathrm{~d}$ and assessed their performance on a spatial memory task. Sucrose consuming rats discriminated between objects in novel and familiar locations when there was a large spatial separation between the objects, but not when the separation was smaller. Neuroproliferation markers in the dentate gyrus of the sucrose-consuming rats were reduced relative to controls. Thus, sucrose consumption impaired aspects of spatial memory and reduced hippocampal neuroproliferation.
\end{abstract}

[Supplemental material is available for this article.]

The hippocampus is critically involved in many learning and memory processes. Hippocampal-dependent forms of learning and memory are particularly vulnerable to the detrimental effects of the overconsumption of high fat and high sugar diets (Molteni et al. 2002; Beilharz et al. 2014; Hsu et al. 2015; Reichelt et al. 2015a,b; Abbott et al. 2016). Furthermore, these detrimental effects can be long lasting. For example, we (Reichelt et al. 2015a) recently demonstrated that rats who consumed $10 \%$ sucrose for $2 \mathrm{~h}$ a day across their adolescence exhibited object-in-place memory deficits assessed $6 \mathrm{wk}$ after cessation of sucrose access.

Memory involves not only remembering information over time, but also keeping memories distinct and minimizing interference among them. The computational process of making nonoverlapping representations of events distinct has been termed "pattern separation" (Marr 1971; Leutgeb et al. 2007; Bakker et al. 2008; Kumaran and McClelland 2012; Kesner 2013). However, more loosely, "behavioral pattern separation" refers to processes that enhance discrimination among similar stimuli (Kent et al. 2016). The dentate gyrus (DG) is a site of adult hippocampal neurogenesis (Kuhn et al. 1996; Cameron and McKay 2001) and is hypothesized to be a neural substrate for behavioral pattern separation processes (Sahay et al. 2011; Tronel et al. 2015). Reductions in adult hippocampal neurogenesis by X-ray irradiation impaired performance when an array of visual target touchscreen stimuli were presented with little spatial separation, but not when the stimuli were more widely separated in space, indicating that neurogenesis is required to discriminate between similar spatial locations (Clelland et al. 2009). Furthermore, high sugar diets have been reported to reduce proliferation of neurons measured by BrdU immunoreactivity in the DG (van der Borght et al. 2011), suggesting that such diets may impair behavioral pattern separation processes.

We examined whether $2 \mathrm{~h}$ daily access to $10 \%$ sucrose (w/vol; CSR white sugar; energy density $1.7 \mathrm{~kJ} / \mathrm{mL}$ ) in young male albino Sprague Dawley rats over a 28 -d period affected

\footnotetext{
${ }^{3}$ Present address: School of Health and Biomedical Sciences, RMIT University, Melbourne, Victoria 3083, Australia Corresponding author: amy.reichelt@rmit.edu.au

Article is online at http://www.learnmem.org/cgi/doi/10.1101/Im.042416. 116.
}

performance on a modified spontaneous location recognition task (SLR) (Bekinschtein et al. 2013, 2014; Kent et al. 2015). The rationale behind the SLR task (see Fig. 1B) is that when objects are closer together in space it is more cognitively challenging to form spatial representations that are distinct, and places greater demands on behavioral pattern separation processes than when the objects are further apart (Bekinschtein et al. 2013, 2014; Kent et al. 2015). This task requires brain-derived neurotrophic factor (BDNF) in the DG to allow the encoding of spatial memories (Bekinschtein et al. 2013, 2014). Thus, such evidence suggests that the SLR task is DG-dependent and sensitive to manipulations of neuroplasticity and depletion of neurogenesis by disrupting Wnt-signaling (Bekinschtein et al. 2013, 2014).

Figure $1 \mathrm{~A}$ shows the timeline of behavioral experiments. Rats in the sucrose consumption group had access to $10 \%$ sucrose solution for $2 \mathrm{~h}$ each day for $24 \mathrm{~d}$, as well on each of the $4 \mathrm{~d}$ of behavioral training and testing. Rats that consumed sucrose did not differ in body weight from control rats $(F<1)$ (Fig. 1C) and the overall energy intake between groups did not differ $(F<1)$, as sucrose consuming rats reduced their chow intake (Fig. 1D). Sucrose intake increased across the 28 -d period (Fig. $1 \mathrm{E}, F_{(3,54)}=$ 60.8, $P<0.001)$.

The SLR task (Fig. 1B) consisted of a 10-min sample phase in which rats were exposed to a familiar gray plastic circular open field arena $(100 \mathrm{~cm}$ diameter $\times 50 \mathrm{~cm}$ high). Three identical objects (A1, A2, and A3-opaque yellow plastic bottles measuring $22-\mathrm{cm}$ high, $8-\mathrm{cm}$ wide), were arranged in a triangle shape (see Supplemental Materials). The arena was surrounded by three distinctive proximal spatial cues (black and white posters with unique patterns $35 \mathrm{~cm}$ high $\times 50 \mathrm{~cm}$ wide, located equidistantly around the arena, and distal cues provided by room furniture). In the d-SLR condition, the distance between each object was equal $(49 \mathrm{~cm})$, whereas in the s-SLR condition A2 and A3 were closer to each other $(20.5 \mathrm{~cm})$ than they were to $\mathrm{A} 1$, which was

C 2016 Reichelt et al. This article is distributed exclusively by Cold Spring Harbor Laboratory Press for the first 12 months after the full-issue publication date (see http://learnmem.cshlp.org/site/misc/terms.xhtml). After 12 months, it is available under a Creative Commons License (AttributionNonCommercial 4.0 International), as described at http://creativecommons. org/licenses/by-nc/4.0/. 
A

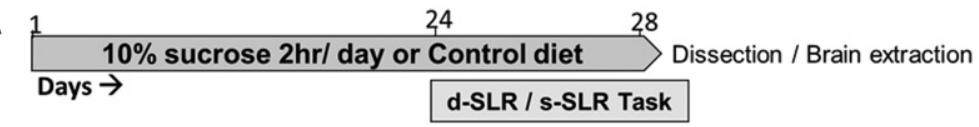

B Spontaneous location recognition (SLR) task
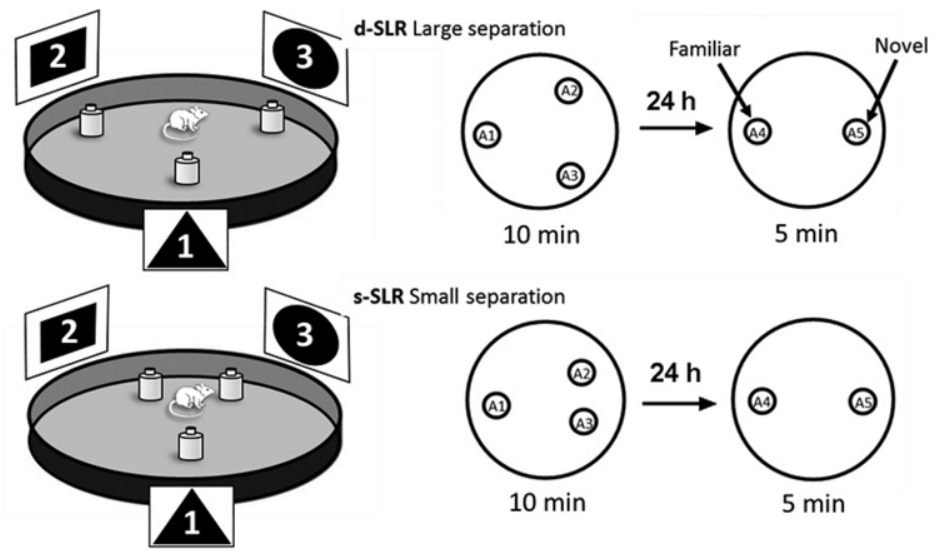

S-SLR Small separation

C

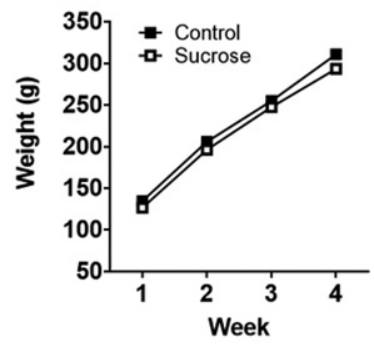

E

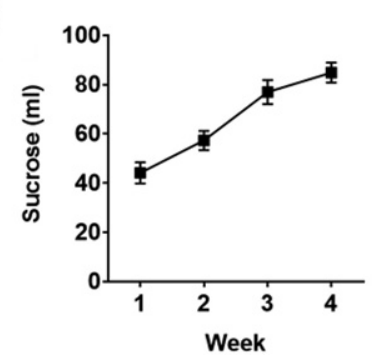

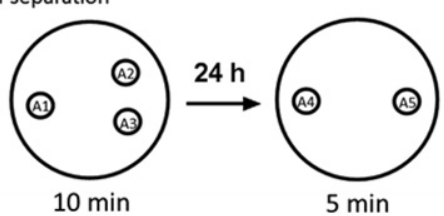

D

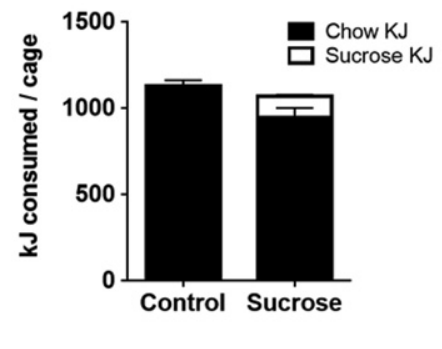

$\mathbf{F}$

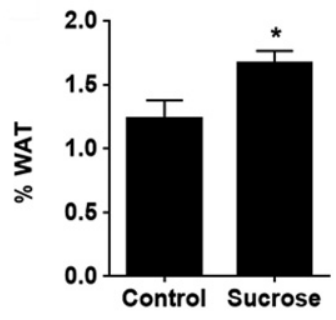

Figure 1. (A) Timeline of experimental events. (B) Schematic of the spontaneous location recognition task showing the relation of the extra-maze cues $(1,2,3)$ and the arrangement of the objects (sample phase: $\mathrm{A} 1, \mathrm{~A} 2, \mathrm{~A} 3$ and test phase: $\mathrm{A} 4, \mathrm{~A} 5)$ in the $\mathrm{d}$-SLR and s-SLR configurations in a 100-cm diameter open field arena. See Supplemental Information for full details of the behavioral methods. $(C)$ Body weights of rats across the sucrose access period. (D) Total energy consumed (kJ) per cage of four rats in each of the diet conditions across a 24-h period. $(E)$ Daily consumption of $10 \%$ sucrose averaged across the three cages (each containing 4 rats) $(F)$ Mean white adipose tissue (WAT) as percentage of body weight in control and sucrose rats. Data are presented as means \pm SEM. $N=12$ per group. $\left(^{*}\right)$ $P<0.05$.

at an equal distance from the other two. Twenty-four hours later, rats were tested. This consisted of rats in both conditions being exposed for 5 min to two identical copies of the sample objects: one of which (A4) remained in the same location as had been occupied by $\mathrm{A} 1$ and the other (A5) located halfway between where A2 and A3 had been located (Bekinschtein et al. 2013). In the d-SLR condition, behavioral pattern separation processes would ensure that representations of the object locations remained distinct from each other. Hence, rats in this condition should be likely to detect the object in the new location and spend more time exploring this novel location. In contrast, in the s-SLR condition, the task confronting pattern separation processes is more difficult. Hence, if the history or sucrose exposure impaired these processes, then rats with this history would be less likely to detect the object in the new location than control rats.

In the d-SLR task control $(N=6)$ and sucrose-exposed $(N=6)$ rats spent equal amounts of time exploring each of the three objects (A1, A2, A3) during the d-SLR sample phase as shown in Figure 2A [no significant main effects of object, group, discrimination $(F \mathrm{~s}<1.0)$; no interactions were significant $(F s<$ 1)]. The control and sucrose-exposed rats performed comparably at testspending more time exploring the object in the novel location (Fig. 2C). This was confirmed statistically by ANOVA which revealed a significant main effect of object $\left(F_{(1,10)}=33.1, P<0.001\right)$, but no significant main effect of sucrose $(F<1)$ or object $\times$ sucrose interaction $(F<1)$.

In the s-SLR task control $(N=6)$ and sucrose-exposed $(N=6)$ rats spent equal amounts of time exploring each of the three objects (A1, A2, A3) during the s-SLR sample phase as shown in Figure 2B [no significant main effects of object, group, discrimination $(F<1)$; no interactions were significant $(F \mathrm{~s}<1)$ ]. However, in the s-SLR task, control rats spent more time exploring the object in the novel location, but sucrose-exposed rats spent equal time exploring the object moved to the new location as the one that remained in the old location (Fig. 2D). Repeated-measures ANOVA demonstrated a significant main effect of object $\left(F_{(1,10)}=30.6, P<0.001\right)$, but no significant main effect of group $\left(F_{(1,10)}=1.2, \quad P=0.31\right)$. A significant object $\times$ group interaction was observed $\left(F_{(1,10)}=30.5, P<0.001\right)$. Simple main effects analysis demonstrated a significant effect of object in control $\left(F_{(1,10)}=\right.$ 61.1, $P<0.001)$ but not sucrose $(F<1)$ rats.

Data were transformed to discrimination ratios (Fig. 2E). Significant main effects of group $\left(F_{(1,20)}=12.6, P<\right.$ $0.01)$, test type $\left(F_{(1,20)}=4.6, P<0.05\right)$, and a significant group $\times$ test interaction $\left(F_{(1,20)}=6.6, P<0.05\right)$ were observed. Simple main effects analysis demonstrated a significant effect of sucrose exposure during the s-SLR $\left(F_{(1,20)}=18.7, P<0.001\right)$ but not the d-SLR test $(F<1)$. Thus, rats exposed to sucrose were able to recall the original layout of the objects when tested $24 \mathrm{~h}$ later as they spent more time exploring the object moved to the new location than the one that remained in its original position.

We then assessed whether daily exposure to sucrose affected cell proliferation in the DG. Twenty-four hours after testing, the brains of sucrose and control rats were analyzed by immunohistochemistry for proliferating cell nuclear antigen (PCNA) and doublecortin (DCX). PCNA is a marker for neuroprogenitor cell proliferation (Olariu et al. 2007; Snyder et al. 2009; Dimitrov et al. 2014), which is expressed during all active phases of the cell cycle and for a short period of time after cells become 
A

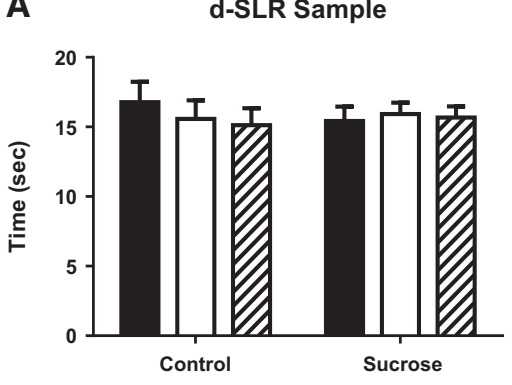

C

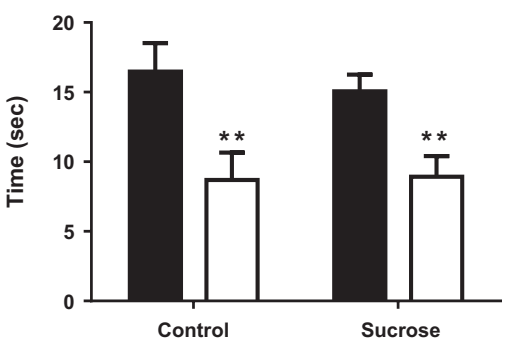

B

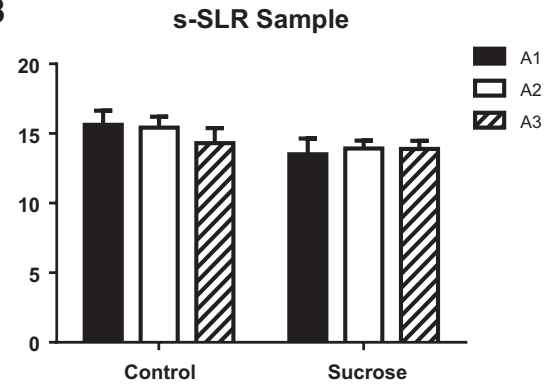

D

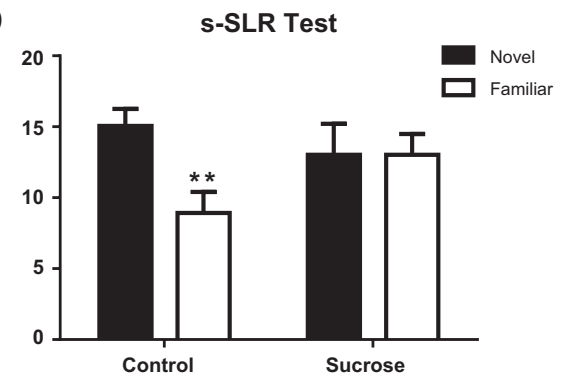

E

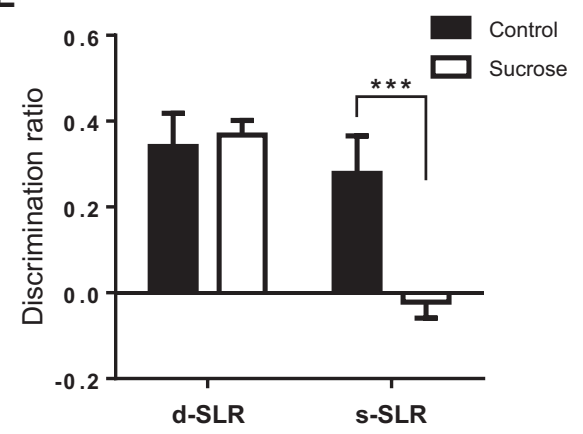

Figure 2. (A) Time spent exploring the three identical objects (A1, $A 2, A 3)$ during the d-SLR sample phase by sucrose-exposed (sucrose) and control rats. (B) Time spent exploring the three identical objects (A1, A2, A3) during the s-SLR sample phase by sucrose-exposed and control rats. (C) Time spent exploring the two identical objects $(A 4, A 5)$ during the d-SLR test phase by sucrose-exposed and control rats. (D) Time spent exploring the two identical objects (A4, A5) during the S-SLR test phase by sucrose-exposed and control rats. (E) Test performance during the d-SLR and s-SLR [D2 discrimination ratio $\left.=\mathrm{Time}_{(\text {novel) }}-\mathrm{Time}_{(\mathrm{familiar})} / \mathrm{Time}_{(\text {novel) }}+\mathrm{Time}_{(\mathrm{familiar})}\right]$ by sucrose consuming and control rats. Data show mean \pm SEM. $\left({ }^{* *}\right) P<0.01,\left({ }^{* * *}\right) P<0.001$ compared with control rats.

post-mitotic (Christie and Cameron 2006; von Bohlen und Halbach 2011). DCX is a microtubule-associated protein that is expressed in migrating neuronal precursor cells (Gleeson et al. 1998; Couillard-Despres et al. 2001) and is used as a marker for new adult born neurons in the DG (Couillard-Despres et al. 2005). Rats that received daily exposure to sucrose for $28 \mathrm{~d}$ had significantly fewer DCX immunopositive cells per DG (DCX+; $t_{(22)}=3.8, P=0.001$, Fig. 3A,B) and PCNA immunopositive cells per DG $\left(\mathrm{PCNA}+; t_{(22)}=2.6, P=0.016\right)$, Fig. $\left.3 \mathrm{C}, \mathrm{D}\right)$ in the granule cell layer of the DG of the hippocampus than control rats.

Analysis of the retroperitoneal and gonadal fat pad weights (Fig. 1F) revealed that rats which consumed sucrose had significantly greater body fat than control rats $\left(t_{(22)}=2.3, P<0.05\right)$. Thus, despite consuming similar amounts of energy, rats that consumed sucrose developed greater adiposity than control rats.

The behavioral results indicated that a history of sucrose consumption spares spatial recognition memory in the d-SLR task. In contrast to this, sucrose consumption impaired test perfor- mance on the s-SLR version of the task when the objects had been located closer to each other during the sample phase, indicating that sucrose had impaired recognition memory. Immunohistochemical analysis of the neuronal proliferation marker PCNA and immature neurons (DCX) showed that consumption of $10 \%$ sucrose reduced proliferating neuronal precursor populations, potentially underpinning the cognitive deficits observed. This is in line with the hypothesis that adult neurogenesis provides an added functionality to the hippocampus when the cognitive load is taxed (Garthe et al. 2016), thus impairments were observed in the s-SLR task, but not in the d-SLR task.

Despite the memory impairment on the s-SLR task in sucrose-consuming rats, proliferating cells were still present in the DG, albeit at a significantly reduced level ( $\sim 80 \%$ of control levels). This complements the observation that performance on cognitive tasks relying on pattern separation, such as a touchscreen location discrimination task, were impaired by both a reduction and a complete ablation of neural differentiation by irradiation. Clelland et al. (2009) infused an anti-Wnt lentivirus into the DG to diminish neuroproliferation in mice. This manipulation produced a $10 \%$ decrease in total cell numbers in the DG and a spatial separation-dependent impairment on the touchscreen task. Moreover, Wnt-knockdown produced performance impairments similar to hippocampal lesions (McTighe et al. 2009) or irradiation-induced ablation of DG neurons (Clelland et al. 2009). Taken together, these results suggest that there is a critical threshold of differentiating neuron populations, below which deficits in pattern separation processes arise (Clelland et al. 2009).

Previous studies have demonstrated that diminishing adult neurogenesis by the lentiviral-induced knockdown of Wnt-signaling impairs performance when the cognitive load for pattern separation was high in the s-SLR task (Bekinschtein et al. 2013). Performance in the xs-SLR task, where the distance between the two objects, A2 and A3, was closer than in the s-SLR, was enhanced by infusion of BDNF into the DG. Furthermore, performance on both the s-SLR and the xs-SLR was enhanced by $14 \mathrm{~d}$ of systemic administration of the orexigenic hormone acyl-ghrelin (Kent et al. 2015). Acyl-ghrelin treatment enhanced both neuroproliferation measured by DCX immunoreactivity and performance on s-SLR when measured 8-10 d after the cessation of treatment (Kent et al. 2015), further indicating that metabolic changes that influence neuroplasticity can modulate performance of this task.

Populations of newborn neurons in the DG are regulated by a variety of factors (Ming and Song 2005). Manipulations that increase the number of newborn granule cells, such as physical activity, are associated with improved cognitive performance in 
A
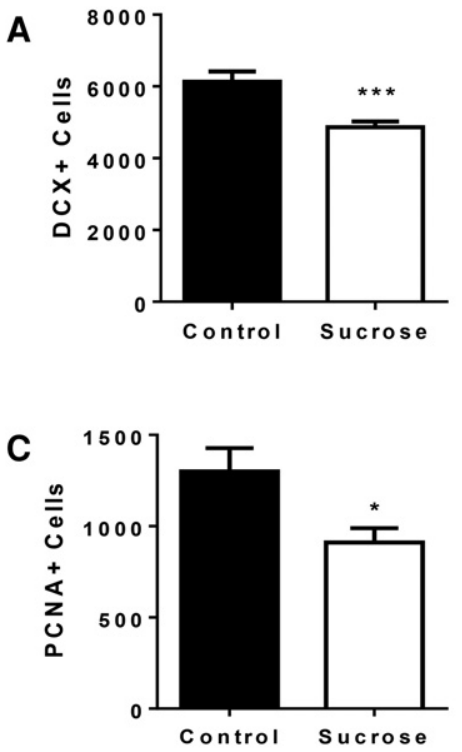

B
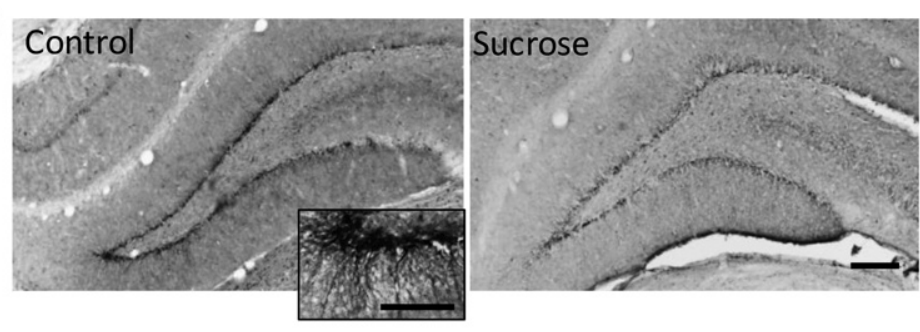

D
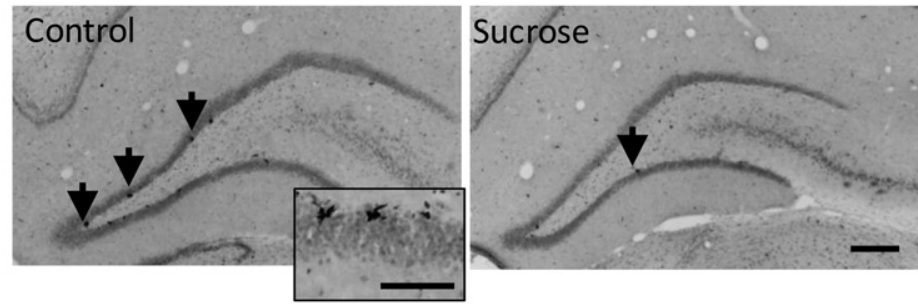

Figure 3. ( $A$ ) Doublecortin-positive $(D C X+)$ cells in the $D G$ of control rats $(N=12)$ and rats sucrose-exposed rats $(N=12)(m e a n \pm S E M)$. ( $B)$ Photomicrographs showing representative doublecortin immunoreactivity in the DG of control and sucrose-exposed rats $(10 \times$, Scale bar $=100 \mu \mathrm{m})$ and inset $40 \times$ Scale bar $=25 \mu \mathrm{m}$. (C) PCNA-positive (PCNA+) cells in the DG of control rats and rats that consumed sucrose (mean \pm SEM). (D) Photomicrographs showing representative PCNA immunoreactivity in the DG of control and sucrose consuming rats $(10 \times$, Scale bar $=100 \mu m$. Arrows show PCNA-positive cells and inset $40 \times$ scale bar $=25 \mu \mathrm{m}) .\left({ }^{*}\right) P<0.05,\left({ }^{* *}\right) P<0.001$ compared with control rats. See Supplemental Information for details of the immunohistochemical methods utilized.

touchscreen discriminations (Creer et al. 2010) and in context fear conditioning where discrimination between shocked and nonshocked contexts (Sahay et al. 2011). Further studies are required to establish the mechanisms by which daily access to sucrose impairs hippocampal function. Continuous consumption of sucrose for $4 \mathrm{wk}$ decreased neurogenesis measured by reduced BrdU immunoreactive cells in the DG (van der Borght et al. 2011), however this more direct assay of neurogenesis was not measured in the current study. Neuroinflammation is another likely candidate as it inhibits neurogenesis (Monje et al. 2003), and high sugar diets increase levels of pro-inflammatory cytokines in the hippocampus (van der Borght et al. 2011; Beilharz et al. 2014; Hsu et al. 2015). Despite consuming similar amounts of energy overall as control rats, the rats that consumed sucrose had increased adiposity. Thus, adipose derived cytokines may have contributed to an enhanced inflammatory state (Park et al. 2005). Additionally, the s-SLR task has been shown to depend on BDNF expression in the DG (Bekinschtein et al. 2013, 2014). As consumption of a high fat/high sugar diet for 8 wk reduced hippocampal BDNF mRNA expression (Molteni et al. 2002), it is possible that the daily access to sucrose in the present experiment likewise reduced BDNF expression in the DG.

The maturation process of newborn neurons takes $\sim 1-2$ mo in rodents (Kempermann et al. 2004), but there are several phases whereby the excitability of these young neurons decrease concomitant with their integration into existing neural circuits (van Praag et al. 2002; Ming and Song 2005). Neuronal excitability is thought to decrease from the time that spinogenesis begins; a time which overlaps with the development of gamma-aminobutyric acid (GABA) receptors (Esposito et al. 2005). Fast-spiking parvalbuminpositive GABAergic interneurons regulate early phases of adult hippocampal neurogenesis (Song et al. 2013). Previously, we observed a reduction in parvalbumin neuron immunoreactivity within the dorsal hippocampus of rats that consumed sucrose on a daily basis (Reichelt et al. 2015a), which may have contributed to the reduced neuroproliferation markers observed here.
The behavioral results indicate that daily intake of sucrose induces deficits in spatial memory when objects are closer together in space, yet spares performance when memory representations are made more spatially distinct. A "cognitive map" describes the spatial representations of an environment (O'Keefe and Dostrovsky 1971; Eichenbaum 2000). The representations between the distal spatial cues and objects, as shown in Figure 1B, may have differed between the d-SLR and s-SLR. During the test phase, the rats may use spatial cue 1 to identify A4 as familiar, whereas the new object A5 does not have a stored association with the extra-maze cues, and hence elicits exploration. Thus, the reduction in the distance between the A2 and A3 objects, during the sample phase in the s-SLR task, also reduced the distances between the extra-maze cues. The question therefore remains whether the critical factor in the s-SLR was the distance between the objects and the extra-maze cues or the distance between the objects themselves. Further studies should examine whether increasing the proximity of the spatial cues to the to-be-remembered locations influences performance in this task.

The present results suggest that daily intake of sugarsweetened drinks has adverse effects on hippocampal-dependent forms of learning that become apparent when "cognitive load" is challenged. Further studies might examine whether treatments and interventions known to promote neurogenesis (such as aerobic exercise) reverse diet-induced cognitive deficits in the s-SLR task. Other measures of behaviors reliant on precursor neuroproliferation and indicative of cognitive flexibility, such water maze reversal learning (Garthe et al. 2009) and spatial separationdependent touchscreen tasks (Clelland et al. 2009) should be assessed.

\section{Acknowledgments}

A.C.R. is the recipient of an Australian Research Council Discovery Early Career Research Award (DE140101071). We thank Kirsten Abbott for her assistance with collection of the behavioral data. 


\section{References}

Abbott KN, Morris MJ, Westbrook RF, Reichelt AC. 2016. Sex-specific effects of daily exposure to sucrose on spatial memory performance in male and female rats, and implications for estrous cycle stage. Physiol Behav. doi: 10.1016/j.physbeh.2016.01.036.

Bakker A, Kirwan CB, Miller M, Stark CE. 2008. Pattern separation in the human hippocampal CA3 and dentate gyrus. Science 319: 1640-1642.

Beilharz JE, Maniam J, Morris MJ. 2014. Short exposure to a diet rich in both fat and sugar or sugar alone impairs place, but not object recognition memory in rats. Brain Behav Immun 37: 134-141.

Bekinschtein P, Kent BA, Oomen CA, Clemenson GD, Gage FH, Saksida LM, Bussey TJ. 2013. BDNF in the dentate gyrus is required for consolidation of "pattern-separated" memories. Cell Rep 5: 759-768.

Bekinschtein P, Kent BA, Oomen CA, Clemenson GD, Gage FH, Saksida LM, Bussey TJ. 2014. Brain-derived neurotrophic factor interacts with adult-born immature cells in the dentate gyrus during consolidation of overlapping memories. Hippocampus 24: 905-911.

Cameron HA, McKay RD. 2001. Adult neurogenesis produces a large pool of new granule cells in the dentate gyrus. J Comp Neurol 435: 406-417.

Christie BR, Cameron HA. 2006. Neurogenesis in the adult hippocampus. Hippocampus 16: 199-207.

Clelland CD, Choi M, Romberg C, Clemenson GD Jr, Fragniere A, Tyers P, Jessberger S, Saksida LM, Barker RA, Gage FH, et al. 2009. A functional role for adult hippocampal neurogenesis in spatial pattern separation. Science 325: 210-213.

Couillard-Despres S, Winkler J, Uyanik G, Aigner L. 2001. Molecular mechanisms of neuronal migration disorders, quo vadis? Curr $\mathrm{Mol} \mathrm{Med}$ 1: $677-688$.

Couillard-Despres S, Winner B, Schaubeck S, Aigner R, Vroemen M, Weidner N, Bogdahn U, Winkler J, Kuhn HG, Aigner L. 2005. Doublecortin expression levels in adult brain reflect neurogenesis. Eur J Neurosci 21: 1-14.

Creer DJ, Romberg C, Saksida LM, van Praag H, Bussey TJ. 2010. Running enhances spatial pattern separation in mice. Proc Natl Acad Sci 107: 2367-2372.

Dimitrov EL, Tsuda MC, Cameron HA, Usdin TB. 2014. Anxiety- and depression-like behavior and impaired neurogenesis evoked by peripheral neuropathy persist following resolution of prolonged tactile hypersensitivity. J Neurosci 34: 12304-12312.

Eichenbaum H. 2000. Hippocampus: mapping or memory? Curr Biol 10: R785-R787.

Esposito MS, Piatti VC, Laplagne DA, Morgenstern NA, Ferrari CC Pitossi FJ, Schinder AF. 2005. Neuronal differentiation in the adult hippocampus recapitulates embryonic development. J Neurosci 25: 10074-10086.

Garthe A, Behr J, Kempermann G. 2009. Adult-generated hippocampal neurons allow the flexible use of spatially precise learning strategies. PLoS One 4: e5464.

Garthe A, Roeder I, Kempermann G. 2016. Mice in an enriched environment learn more flexibly because of adult hippocampal neurogenesis. Hippocampus 26: 261-271.

Gleeson JG, Allen KM, Fox JW, Lamperti ED, Berkovic S, Scheffer I, Cooper EC, Dobyns WB, Minnerath SR, Ross ME, et al. 1998. Doublecortin, a brain-specific gene mutated in human X-linked lissencephaly and double cortex syndrome, encodes a putative signaling protein. Cell 92: $63-72$.

Hsu TM, Konanur VR, Taing L, Usui R, Kayser BD, Goran MI, Kanoski SE. 2015. Effects of sucrose and high fructose corn syrup consumption on spatial memory function and hippocampal neuroinflammation in adolescent rats. Hippocampus 25: 227-239.

Kempermann G, Wiskott L, Gage FH. 2004. Functional significance of adult neurogenesis. Curr Opin Neurobiol 14: 186-191.

Kent BA, Beynon AL, Hornsby AK, Bekinschtein P, Bussey TJ, Davies JS, Saksida LM. 2015. The orexigenic hormone acyl-ghrelin increases adult hippocampal neurogenesis and enhances pattern separation. Psychoneuroendocrinology 51: 431-439.

Kent BA, Hvoslef-Eide M, Saksida LM, Bussey TJ. 2016. The representational-hierarchical view of pattern separation: not just hippocampus, not just space, not just memory? Neurobiol Learn Mem 129: $99-106$

Kesner RP. 2013. Role of the hippocampus in mediating interference as measured by pattern separation processes. Behav Processes 93: 148-154.

Kuhn HG, Dickinson-Anson H, Gage FH. 1996. Neurogenesis in the dentate gyrus of the adult rat: age-related decrease of neuronal progenitor proliferation. J Neurosci 16: 2027-2033.

Kumaran D, McClelland JL. 2012. Generalization through the recurrent interaction of episodic memories: a model of the hippocampal system. Psychol Rev 119: 573-616.

Leutgeb JK, Leutgeb S, Moser MB, Moser EI. 2007. Pattern separation in the dentate gyrus and CA3 of the hippocampus. Science 315: 961-966.

Marr D. 1971. Simple memory: a theory for archicortex. Philos Trans $R$ Soc Lond B Biol Sci 262: 23-81.

McTighe SM, Mar AC, Romberg C, Bussey TJ, Saksida LM. 2009. A new touchscreen test of pattern separation: effect of hippocampal lesions. Neuroreport 20: 881-885.

Ming GL, Song H. 2005. Adult neurogenesis in the mammalian central nervous system. Annu Rev Neurosci 28: 223-250.

Molteni R, Barnard RJ, Ying Z, Roberts CK, Gomez-Pinilla F. 2002. A high-fat, refined sugar diet reduces hippocampal brain-derived neurotrophic factor, neuronal plasticity, and learning. Neuroscience 112: $803-814$.

Monje ML, Toda H, Palmer TD. 2003. Inflammatory blockade restores adult hippocampal neurogenesis. Science 302: 1760-1765.

O'Keefe J, Dostrovsky J. 1971. The hippocampus as a spatial map. Preliminary evidence from unit activity in the freely-moving rat. Brain Res 34: 171-175.

Olariu A, Cleaver KM, Cameron HA. 2007. Decreased neurogenesis in aged rats results from loss of granule cell precursors without lengthening of the cell cycle. J Comp Neurol 501: 659-667.

Park HS, Park JY, Yu R. 2005. Relationship of obesity and visceral adiposity with serum concentrations of CRP, TNF-alpha and IL-6. Diabetes Res Clin Pract 69: 29-35.

Reichelt AC, Killcross S, Hambly LD, Morris MJ, Westbrook RF. 2015a. Impact of adolescent sucrose access on cognitive control, recognition memory, and parvalbumin immunoreactivity. Learn Mem 22: 215-224.

Reichelt AC, Maniam J, Westbrook RF, Morris MJ. 2015b. Dietary-induced obesity disrupts trace fear conditioning and decreases hippocampal reelin expression. Brain Behav Immun 43: 68-75.

Sahay A, Scobie KN, Hill AS, O'Carroll CM, Kheirbek MA, Burghardt NS, Fenton AA, Dranovsky A, Hen R. 2011. Increasing adult hippocampal neurogenesis is sufficient to improve pattern separation. Nature 472: $466-470$.

Snyder JS, Choe JS, Clifford MA, Jeurling SI, Hurley P, Brown A, Kamhi JF, Cameron HA. 2009. Adult-born hippocampal neurons are more numerous, faster maturing, and more involved in behavior in rats than in mice. J Neurosci 29: 14484-14495.

Song J, Sun J, Moss J, Wen Z, Sun GJ, Hsu D, Zhong C, Davoudi H, Christian KM, Toni N, et al. 2013. Parvalbumin interneurons mediate neuronal circuitry-neurogenesis coupling in the adult hippocampus. Nat Neurosci 16: 1728-1730.

Tronel S, Lemaire V, Charrier V, Montaron MF, Abrous DN. 2015. Influence of ontogenetic age on the role of dentate granule neurons. Brain Struct Funct 220: 645-661.

van der Borght K, Kohnke R, Goransson N, Deierborg T, Brundin P, Erlanson-Albertsson C, Lindqvist A. 2011. Reduced neurogenesis in the rat hippocampus following high fructose consumption. Regul Pept 167: 26-30.

van Praag H, Schinder AF, Christie BR, Toni N, Palmer TD, Gage FH. 2002. Functional neurogenesis in the adult hippocampus. Nature 415: 1030-1034.

von Bohlen und Halbach O. 2011. Immunohistological markers for proliferative events, gliogenesis, and neurogenesis within the adult hippocampus. Cell Tissue Res 345: 1-19.

Received March 22, 2016; accepted in revised form April 27, 2016. 


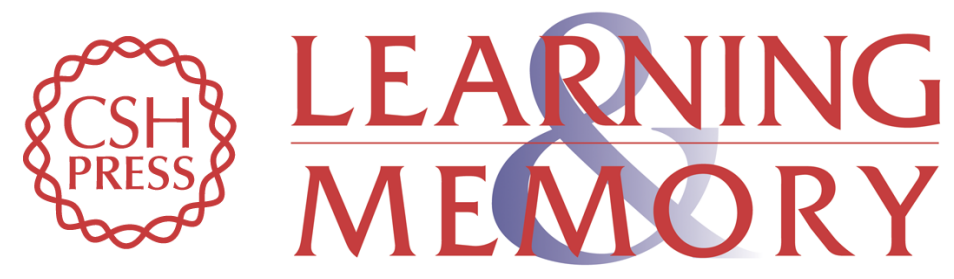

\section{Daily access to sucrose impairs aspects of spatial memory tasks reliant on pattern separation and neural proliferation in rats}

Amy C. Reichelt, Margaret J. Morris and Reginald Frederick Westbrook

Learn. Mem. 2016, 23:

Access the most recent version at doi:10.1101/Im.042416.116

\section{Supplemental http://learnmem.cshlp.org/content/suppl/2016/06/16/23.7.386.DC2 Material}

References This article cites 42 articles, 10 of which can be accessed free at: http://learnmem.cshlp.org/content/23/7/386.full.html\#ref-list-1

Creative This article is distributed exclusively by Cold Spring Harbor Laboratory Press for the Commons first 12 months after the full-issue publication date (see

License http://learnmem.cshlp.org/site/misc/terms.xhtml). After 12 months, it is available under a Creative Commons License (Attribution-NonCommercial 4.0 International), as described at http://creativecommons.org/licenses/by-nc/4.0/.

Email Alerting Receive free email alerts when new articles cite this article - sign up in the box at the Service top right corner of the article or click here. 